\title{
Study on Cloud Model of Interactive Programming Learning to Improve the Interest of Higher Vocational Students
}

\author{
Liu Xingxing ${ }^{1, a}$, , Yang Chenggang ${ }^{2, b}$ \\ ${ }^{1}$ Department of Information Engineering, Private Sichuan Tianyi College, Cheng Du, China \\ ${ }^{2}$ School of Marxism, Wuhan University of Technology, Wuhan, China \\ aemail:342270413@qq.com, bemail:1274297207@qq.com, \\ *corresponding author
}

Keywords: cloud computing, programming design specialty, practical ability, online interactive programming, real-time feedback: improving interest

\begin{abstract}
For the software design specialty in higher vocational college, what it mainly cultivates is the high-technology applied talents, focusing on cultivating the practical abilities of students. However, that's also the place that exists difficulty. In order to improve the enthusiasm of hands-on programming of students, in this paper, the online interactive programming learning mode based on cloud environment was proposed, which is a means for students to verify whether or not they have mastered the technology immediately after learning the knowledge by means of online programming, and a real-time interactive model that can greatly enhance hands-on practice of students. It takes advantage of overcoming a learning scenario similar to the overcoming all the difficulties in the way to allow students to carry out practical exercises unconsciously. It not only trains their actual development capabilities, but also helps teachers to better improve the quality of teaching.
\end{abstract}

\section{Research Background of Online Interactive Programming Learning}

\subsection{Necessity}

The practical ability of the programming design major is of great significance ${ }^{[1]}$. Exquisite and more practice is the basic principle of programming design curriculum teaching. Only through a certain amount of hands-on operations can students continuously improve their coding ability, which is in accordance with the teaching concept of constructing teacher to guide and take the learning of students as the center. However, in the process of actual teaching, because the students in higher vocational college has poor foundation and poor enthusiasm in learning, so that they have difficulty in enhancing interest when they are faced up with the more difficult courses of program design, especially in terms of concepts, principles, and logic analysis, such knowledge, they have little interest in them. The real reason after thinking is still the lack of exploration of interests of students. First of all, it's necessary to let them generate interest in learning, especially the interest in programming, and then teach them more knowledge, thereby forming a virtuous circle and achieving a multiplier effect. In terms of statistics, it's true that lots of higher vocational colleges have also intensified the operational procedures of the program design courses and achieved certain teaching results. However, there are still many difficulties in practical training teaching organization and investment in practical training, and there is generally fearful emotion of hands-on programming practice for students, and a sense of achievement are not easy to get satisfaction. It is because of the existing problems and deficiencies that reflect the necessity of this research.

\subsection{Analysis of research status at home and abroad}

Lots of colleges and universities have gradually attached importance to the practical training of program design courses, especially the vocational school which have increased the proportion of practical classes, and specifically designed teaching arrangement of practical courses at the same time, including the preparation of practical training programs, and other various attempts, which 
have also achieved good results ${ }^{[2]}$.

In the professional courses on software specialty, such as data structures, C language programming, database principles and applications, Java language programming and other courses, which have been arranged more practical training courses and there is any no possibility for these courses to adopt traditional teacher manually assessment On the one hand, it's time consuming, on the other hand, students can't gain the most timely feedback. Based on this context, some 211,985 universities launched an online testing system similar to the ACM competition, however, there are two major problems for their online testing system.

\subsubsection{The practice system of algorithmic competition doesn't apply to all students in programming design}

\subsubsection{The practice system of elite universities is even less suitable for students who are from higher vocational colleges}

In terms of consulting relevant materials and papers, it's found that there is still little study on "the online interactive programming learning that improves the learning interest of college students from higher vocational colleges" and there is no anyone to study it, which is also the value and innovation of this article. .

\subsection{Research objective}

Currently speaking, the on-line evaluation system of the 211,985 universities is not suitable for private colleges and universities, and the level of students in the higher vocational colleges is different from them. As a consequence, their systems cannot be used directly. Therefore, it's necessary for us to exclusively build an online learning platform for the higher vocational colleges in order to motivate the enthusiasm of students in learning and urge them to complete the practical training. According to the difficulty of the subject, it needs to be step by step, from easy to difficult. The objective and pattern of online interactive programming learning

\section{Objective}

In the process of teaching, different teaching methods are adopted in accordance with different teaching contents, that is, the basic introduction knowledge and basic concepts adopt traditional teaching methods.

After students have a preliminary concept of programming, it mainly takes advantage of the case methods to dilute the teaching of grammar rules so that students can have a good command of the idea methods of program design. The mastery of concepts and grammar rules runs through the analysis, writing, and debugging of programs.

In the course of practice, students adopt the "online interactive programming learning platform that improves the interest of learning for college students based on the cloud environment" proposed by this article, when they overcome all difficulties in the way and have a good command of knowledge, they will acquire a sense of accomplishment.

\section{Mode}

This subject is aimed at some of the problems exposed in the initial teaching reform attempt. What the most prominent problem is that there is insufficient time for students to carry out the computer experiment. Taking the Java course as an example. There were 96 hours in one semester at total, 64 hours in theory, 32 hours in practice, 32 hours in class, which doesn't far meet the time requirements for students to practice on the machine, it can only require students to use the time after classes to practice, however, there aren't too many chances for students to ask their teachers questions directly,just like the class, when students get feedback at the first time, they can modify them immediately and continue to practice. The practice of programming design is not like the writing practice of liberal arts. As long as there is a problem in one place, the function behind it cannot be done. It can only be continued after it's resolved, which is the main reason that students can't complete their homework in class. The situation has also negative influence on students' enthusiasm for learning so that their interest in learning will slowly be reduced and the follow-up courses will be very unfavorable. 
In terms of the above reasons, learning from domestic and foreign famous online interactive learning websites for reference researches and develops an on-line interactive programming learning platform based on cloud environment to promote the self-learning ability and learning interest of college students, which is helpful to solve the problem of computer experiment of student after school, and reduce the difficulty of experimental teaching organization, and improve the efficiency of experimental teaching. Specifically speaking, the research framework of this paper is as follows ${ }^{[3]}$ :

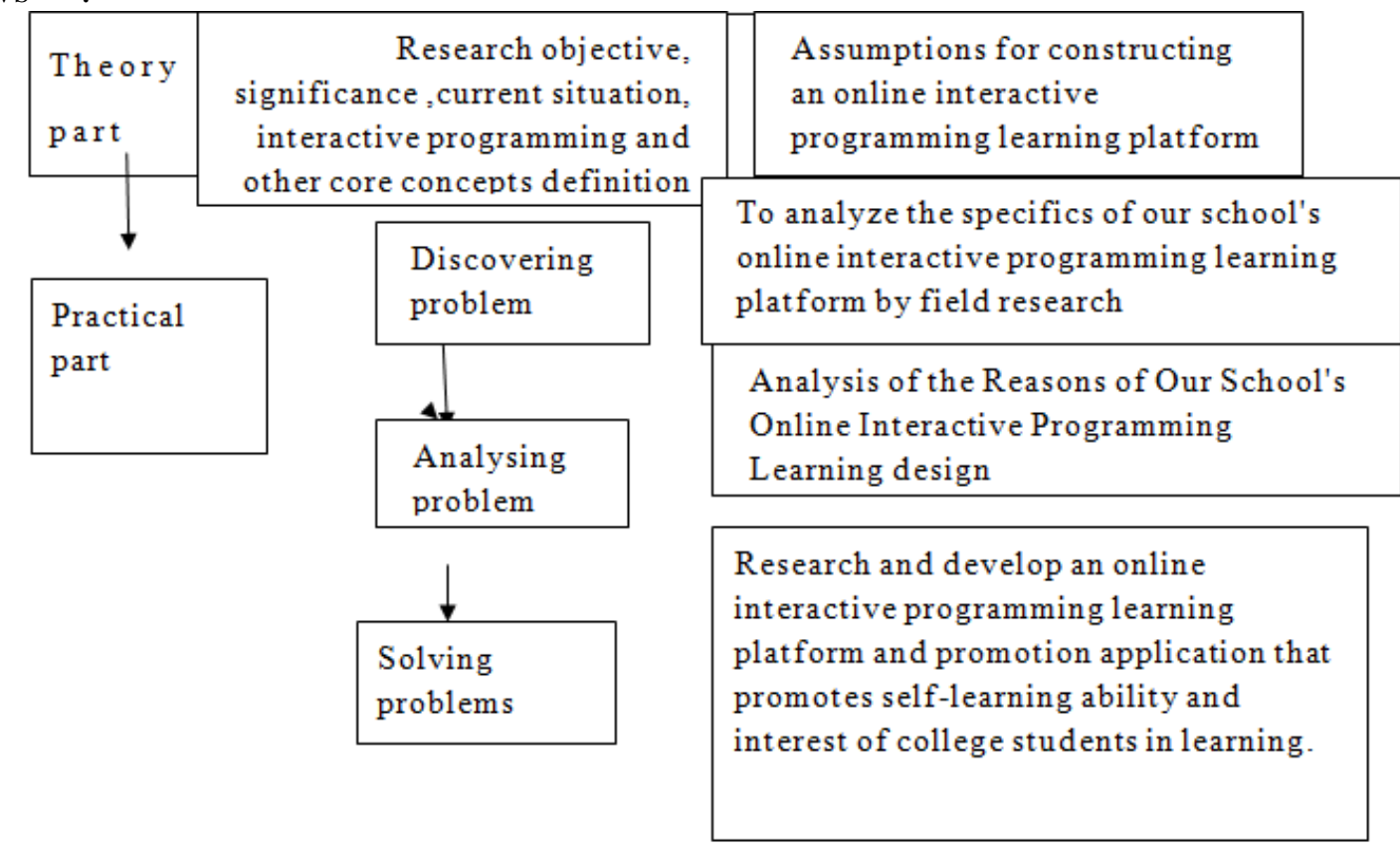

Figure 1 this is Overview Diagram of Study Content

\section{Speciality and Innovation}

\subsection{Extensive platform users}

At present, the users of the online programming platform in China are single, and it is not able to provide online programming learning for campus and off-campus users at the same time. The learning platform is developed by means of java language and it uses mysql database. The social ordinary registered users and students who are in colleges and universities can learn programming skills and raise programming skills through the platform. The students in the colleges and universities can not only use the function of social ordinary users, but also can use it for teaching.

\subsection{Significant anti-cheating features.}

Even though the common online learning system is installed in experiments or exams, if students share their account passwords, it is easy to get answers from others. The learning system has developed a unique "anti-cheating" function: After the user logs in, he or she will need to answer on the system, but the content of the answer cannot be copied and pasted, which is helpful to prevent students from sending the answer to other students. In addition, the system has added the same-answers monitoring function and once it's found that there is the same answer, the teacher is notified to review it, and the teacher can perform human assessment again to confirm.

\subsection{To improve the fairness of the number of test scores in the teaching test.}

In the general ACM online evaluation system, because it is to review the papers through machine, the program will appear zero point as long as there is a little error, which is good for competition, however, it is not desirable for students to do homework, so the system provides reference answers for students so that it cannot compete with the final result when reviewing, but the content of the answer will be competed. If it's found that most of answers are the same as most of the reference 
answers, it will remind teachers of implementing manually review in order to avoid causing negative impact on the enthusiasm and active attitude of students for learning.

There is a certain degree of difficulty for the programming course itself and the concept and knowledge is very abstract. In addition to the teaching way that teachers should explain the profound things in a simple way, it's necessary for them to come up with methods to improve their hands-on programming skills ${ }^{[3]}$. This system allows students to verify what they are currently learning. Each pass is passed, which means that it's passed this difficulty, so that there is a feeling of overcoming all the difficulties in the way and the interest in learning for students will be raised.

\section{Conclusion and Prospect}

The design of the interactive programming service system relies on the guidance of cloud learning ideas, and its ultimate goal is to provide a professional, interesting, and ubiquitous learning environment for the majority of programming beginners. For program design courses, it provides the special features such as "cloud compilation”, "cloud learning guidance”, and "cloud resource management" etc ${ }^{[4]}$.

Under the idea of platform-as-a-service and software-as-a-service, learners can freely write program, compile and run code on PC-end, mobile-end and other terminals, and get timely feedback. In the later period, it can also be added to teacher online question-answering, student exchange areas and other functions, which makes the learning atmosphere more intense and further improve the learning quality and efficiency.

\section{References}

[1] Yang Kai, Wang Jingshu, Yang Zhao, etc. The exploration to improve the practical ability of college students [J]. Human Resources Management. 2010, (3): 71-72.

[2] Wang Xuqing. Learning Programming, Programming Assistance- A Review of Harvard Scratch Tutorial in 2014 [J]. Modern Educational Technology. 2016, (5).

[3] Mou Lianjia, Li Pixian, Shao Hongyan. Study on the learning methods of junior college students in programming [J].Senior-Engineering Teaching Research, 2014,

[4] Zhang Yuanyuan, Lu Hongwei, Li Yanping. Study of Application of learning community in Java programming curriculum research [J]. Heilongjiang Animal Husbandry and Veterinary Medicine, 2016, (01): 178-180.

[5] Wu Dongqin, Liu Yuhan, Li Jia. Design of Interactive Programming Service System under the Cloud Learning Concept [J]. Chinese Education Information 2016, (3). 